Session FA1-1

\title{
Helping Teachers Use Professional Learning Communities to Infuse Project Based Learning into the K-12 Curriculum
}

\author{
James (“Jim”) R. Morgan, Luciana R. Barroso, \\ Zachry Department of Civil Engineering \\ Texas A\&M University, College Station, TX 77843-3136 \\ Kristin S. Huggins \\ Department of Educational Administration and Human Resource Development \\ Texas A\&M University, College Station, TX 77843-4226
}

\begin{abstract}
The experiences from National Science Foundation funded engineering coalitions, and other engineering education projects, can certainly apply to math and science education. Moreover, the projects used in first year engineering courses can be used to bring "reality" to the interdisciplinary project-based learning initiatives in secondary education. Faculty, both high school and college, can work together:

- $\quad$ to design learning experiences for students;

- $\quad$ to explore alternative teaching pedagogies;

- $\quad$ to explore strategies for motivating students; and

- $\quad$ to find ways to connect student learning experiences to real-world problem solving.

When both innovative and complex pedagogies are introduced to teachers, apprehension is often the first response. These innovative and complex pedagogies often require a paradigm shift in reconceptualizing their role as a teacher. Due to this difficulty, tapping both individual and collective capacity are best within the context of professional learning communities (PLCs), which are characterized by shared norms and values, reflective dialogue, de-privatization of practice, collective focus on student learning, and collaboration. These PLCs set the foundation, so teachers can begin inquiry into their practice in a new way for increased student learning.

The integration of Professional Learning Communities and Project-Based Learning serve to address the issues discussed above. Currently, the North Texas STEM (Science, Technology, Engineering and Math) Center is collaborating with the Waco Independent School District to incorporate Project-Based Learning (PBL) through the development of Professional Learning Communities (PLCs) in their high schools. While PLCs can assist with any reform effort, when implementing Project-Based Learning, they are especially significant due to the amount of time and resources needed to create projects, both within a discipline and even more so, between disciplines. With the support structure of a PLC, teachers can leverage their efforts into those occurring in other classes, allowing for richer learning experiences for the students while mitigating the work-load and risk to any individual teacher.
\end{abstract}




\section{Introduction}

There has been increasing concern over the possibility that lack of preparation will reduce the ability of the United States to compete in a world where the international economic playing field is now "more level" than it has ever been ${ }^{1}$. The Texas High School Project (THSP) ${ }^{2}$ was created to address this need by boosting graduation rates and increasing the number of Texas high school students prepared for college, work, and citizenship. The THSP focuses its efforts on high-need schools and districts statewide, with an emphasis on urban areas and the Texas-Mexico border. Public and private organizations involved in the effort include the Texas Education Agency, the Governor's Office, the Texas Legislature, the Bill \& Melinda Gates Foundation, the Michael \& Susan Dell Foundation, Communities Foundation of Texas and National Instruments.

One of the initiatives of the THSP is the development of Texas-Science, Technology, Engineering and Math (T-STEM) programs. This initiative builds on state and local efforts to improve achievement in math and science, as well as increasing the number of students entering STEM careers ${ }^{2}$. Funding was awarded to establish T-STEM Centers at five geographically different locations. These centers train not only the T-STEM academy teachers but any teacher and administrator in the state of Texas on how to integrate rigor into the classroom and still address the Texas Essential Knowledge and Skills (TEKS) mandated by the Texas curriculum. One of the five centers is the North Texas STEM (Science, Technology, Engineering and Math) Center (NT-STEM Center). The NT-STEM Center is a partnership of Texas A\&M University and several Texas Independent School Districts that promotes STEM education by researching, creating, and providing information on best practices for innovative teaching and learning.

The focus of the NT-STEM Center is to work specifically with urban schools whose student population is composed primarily of at-risk students, from low income and minority backgrounds. The specific goals and objectives of the NT-STEM Center include: (1) raising achievement levels in Math and Science, (2) enhancing critical thinking skills, and (3) raising internal expectations of academic success for both students and teachers.

Each high school working with the NT-STEM Center has a design team composed of a professor of education, a STEM professor, and graduate students. All of the education faculty and most of the graduate students in the teams have years of high school teaching experience. The composition of these teams allows for perceived credibility, STEM content expertise, pedagogical knowledge, and models cross-disciplinary collaboration.

The approach chosen for the NT-STEM Center is to incorporate project-based learning as a tool to achieve goals through making learning relevant and exciting! Implementing rigorous teaching and learning requires a balanced approach to teaching, where teachers must strike a balance between lower levels of learning (such as the identification of facts) where foundational concepts must be understood and higher levels of learning (such as critical thinking) where deeper understanding of the subject knowledge is required. This rigorous kind of teaching and learning often is found in engineering projects. Engineering projects naturally incorporate a real-world context for STEM concepts to be applied, as mathematics and science are tools utilized by engineers. When those projects allow for open-ended approaches and solutions, they require students to think and creatively integrate their knowledge from a variety of classes.

Proceedings of the 2009 ASEE Gulf-Southwest Annual Conference Baylor University

Copyright $\Subset$ 2009, American Society for Engineering Education 
However, when both innovative and complex pedagogies are introduced to teachers, apprehension is often the first response. Nevertheless since teachers are the most significant factor in student learning, they must overcome their apprehension to recreate their practice. Yet, teachers cannot change practice unless they build capacity. Practice requires a paradigm shift in conceptualizing of their role as a teacher. Both individual and collective capacity are best continuously pursued within the context of professional learning communities (PLCs), which are characterized by shared norms and values, reflective dialogue, de-privatization of practice, collective focus on student learning, and collaboration. These PLCs set the foundation, so teachers can begin inquiry into their practice in a new way for increased student learning. This kind of foundation is specifically significant in STEM work that often requires the knowledge and skills of a cadre of teachers to design and implement effective projects that cross several disciplines that are often in silos in secondary education. Additionally, even STEM projects that are within-subject content alone, require a great deal of expertise to create. Therefore, the need arises for several teachers to work in collaboration with each other in the process of the design, similarly to what the teachers are asking the students to do in their work groups on projects.

The experiences from National Science Foundation funded engineering coalitions, and other engineering education projects, can certainly apply to math and science education. Moreover, the projects used in first year engineering courses can be used to bring "reality" to the interdisciplinary project-based learning initiatives in secondary education. Faculty, both high school and college, can work together:

- $\quad$ to design learning experiences for students;

- $\quad$ to explore alternative teaching pedagogies;

- $\quad$ to explore strategies for motivating students; and

- $\quad$ to find ways to connect student learning to real-world problem solving.

The NT-STEM Center is a partnership bringing together school campus and district administrators, teachers, students, STEM professors, STEM business partners, community-based informal STEM institutions such as museums and existing science networks in order to provide opportunity for interaction between all of these stakeholders. The NT-STEM Center provides guidance and support for the formation of PLCs. Project-based learning is introduced to teachers in that framework, where efforts of individual teachers are leveraged off one another. Benefits to engineering include (1) students who are better prepared academically, and (2) increased understanding of what engineers do by both students and teachers.

\section{Professional Learning Communities}

Professional learning communities (PLCs) come from the concept of organizational learning ${ }^{\text {[1-5] }}$ that contends organizations, like educational organizations, need to be in a process of reevaluating the basic premises that guide organizational behavior in order to increase their organizational knowledge base. Through organizational learning processes, educational institutions routinely examine and question values that guide organizational actions ${ }^{[5]}$, generate new insights and knowledge ${ }^{[3,4]}$, and improve organizational memory, as well as build capacity for effectiveness and dissemination of knowledge ${ }^{[1]}$. PLCs exist ${ }^{[6,7]}$ within learning organizations. Generally, they are collective groups of educators with "a commitment to lifelong 
professional learning and collective responsibility for improved student learning” [8] Specifically, they are groups of educators who meet together on a consistent basis to inquire, interrogate, and challenge current pedagogical practices, usually based upon informal or formal data gathered, in order to reform practice for student academic success. In high schools, PLCs are usually constructed of teachers with similar content knowledge who can serve as critical friends to their colleagues. However, cross-curricular PLCs are essential to creating an academic experience for students that places knowledge in content-connected conceptual frameworks instead of disconnected silos.

PLCs serve as a reform effort due to their potential to provide essential just-in-time professional development. Typically, professional development is provided to teachers in one or two-day increments on differing topics each time or week-long seminars usually held during summer months. Often, teachers attend these professional development sessions by themselves or with one or two other teachers from their school. After attending these professional development sessions, little dissemination of information occurs. Thus, one or more teachers grow professionally if they choose to implement the ideas provided to them, while their colleagues have no idea what they have learned unless haphazard conversations occur in which the learning is shared. However, research on professional development has shown that eight to ten days of continuous professional development spread throughout the year with the colleagues with whom one works on a daily basis and can hold each other accountable due to collectively gained knowledge has the best potential to change practice ${ }^{[9]}$. Therefore, the premise underlying PLCs is that daily professional development with colleagues within the same context on daily pedagogical challenges can provide an even better means of improving practice due to the timely addressing of teaching concerns. Whereas professional and educational networks external to the school serve as important systems of collegial support, professional community "offers the more inclusive support of whole school" ${ }^{[10]}$, promoting collaboration among staff members, breaking down barriers that isolate the educators in their work, and supporting improved professional practices. In fact, PLCs provide ongoing, daily professional development that external professional development cannot provide.

Creating PLCs requires structural resources because communities, even mandated ones, need to have systems in place to help them to form before any reformation of practice can occur. Some of the structural resources that are needed are time to meet, proximity of classrooms, communication structures, autonomy to change practice, and interdependent roles ${ }^{[6]}$. Within many schools, time to meet becomes a problematic financial concern. Since teachers are guaranteed to have a conference or planning period in most school districts based upon contractual requirements, schools have to find other times for teachers to meet together. The time for PLCs to meet within the school day is optimum because when teachers meet before or after school, the timing often conflicts with personal obligations like dropping off or picking up children from school or professional obligations such as tutoring or coaching. If time is allotted during the school day, distractions from the PLC goals and objectives are less likely to occur. However, many school districts struggle with a way to financially provide two periods off a day for each teacher and still have the necessary sections of classes to include all of the students. Aside from time, teachers also need to be located within the school building next to teachers who are part of the PLC. This allows for impromptu conversations and collaborations to occur between classes. Additionally, it saves time in the PLC gathering together because they are

Proceedings of the 2009 ASEE Gulf-Southwest Annual Conference Baylor University

Copyright $\Subset$ 2009, American Society for Engineering Education 
conveniently located close to one another. Once time is allotted and teachers are put within proximity of one another, both formal and informal communication structures need to be created. While many informal communications will occur throughout the school days due to close proximity, formal structures concerning emails, agenda items, etc. need to be discussed collectively by the group and agreed upon. If resources are needed, formal communication structures for gaining assistance from administrators need to be in place as well as a general understanding of response time to concerns or questions. Teachers also need to have interdependent roles. Teaching can be very isolating, especially when teachers are fully aware that they will be evaluated during the year based upon their individual practice. Thus, traditionally and even recently, teachers have worked alone to improve their own individual practice with an eclectic, often non-cohesive, smattering of opportunities to be professionally developed. However, in the twenty-first century, the myriad of expectations put on teachers from national policy, state mandates, and local communities requires teachers to rethink their autonomous roles to be more integrated with and interdependent on their colleagues. Thus, PLCs as collective wholes need to have the autonomy to change their practice and feel empowered by administration to do so.

Aside from structural resources, PLCs also need social and human resources which include openness to improvement, trust and respect, access to expertise, supportive leadership, and socialization ${ }^{[6]}$. After the implementation of No Child Left Behind Act (NCLB), most public schools have supportive leadership for change and have an openness to improvement because it is required, especially if schools are not meeting Annual Yearly Progress (AYP) required by NCLB. How that support and openness are manifested vary. However, for genuine improvement and success at reformation, schools have to have a continuous "learning" stance ${ }^{[11]}$ regardless of outside mandates to meet the needs of the ever-changing knowledge and skills needed to make today's youth not only successful in academics, but successful in their careers and as citizens. Trust and respect are the foundations of creating any community. Yet, these conditions do not simply manifest themselves. They have to be consciously cultivated. Additionally, expertise has to be cultivated. Traditional forms of teacher identity have been variously constructed as "sage on the stage" models. However, sages no longer exist within teaching. Experience brings expertise, but so do new teachers. But, new teachers have to be socialized to PLCs, even if they question their construction through the new learning they bring to those communities.

Effectively functioning PLCs have five characteristics ${ }^{[10]}$. These characteristics are distinctive of and critical to professional community, and they include shared norms and values, focus on student learning, reflective dialogue, deprivatization of practice, and collaboration. From the outset, PLCs need to establish norms and values that are created and shared by the entire community. Some of these norms will involve who facilitates the discussion, who creates the agenda, or even who takes minutes on the events that occur. Additionally, values must be discussed and accountability for acting in ways that align with those values. Some of those values include beliefs about student's abilities to learn, beliefs about the responsibilities of educators for students' learning or even the beliefs about professional conduct. These shared norms and values need to be stated and written as the foundation of the PLC. Once shared norms and values have been established, the focus of any PLC must be clearly toward improving student learning. Schools are often a myriad of competing distractions. However, creating successful student learning opportunities is the reason schools were even created. This focus

Proceedings of the 2009 ASEE Gulf-Southwest Annual Conference Baylor University

Copyright (c) 2009, American Society for Engineering Education 
must be maintained. PLCs provide a venue for public focus on student learning through reflective dialogue with colleagues about student learning successes and challenges. Through using the community to reflect on practice, considerations for ways of thinking about that practice can be multi-vocal. Additionally, successful PLCs seek to move their pedagogy even deeper for greater student achievement by not simply addressing student learning successes and challenges with their colleagues, but by allowing their colleagues to come and observe their practice to provide critical input based upon their observation. Reflective dialogue and deprivatized practice can only occur through collaboration. Most teachers are willing to cooperate with one another by sharing lesson plans or covering a colleague's class when emergencies arise. Additionally, some teachers are even collegial. They are willing to discuss professional issues with other teachers. However, true collaboration comes when teachers view their roles as interdependent and must collaborate to ensure learning for all of the students in the school.

While there has been minimal research on PLCs, there has been research that indicated that PLCs can actually improve classroom teaching across a team of teachers ${ }^{[12]}$. Thus, PLCs are important because they have the potential to change practice in not only a more timely way, but in a more effective way than traditional professional development since teachers have to address and be accountable for the practice in which they engage every day. Additionally, PLCs provide a place for data-driven decision making that has become the focus of schools since NCLB. Schools regularly and most often, weekly, take benchmark tests to let them know where their students' current learning challenges exist. Through having this data readily available, teachers constantly know the weaknesses of their students and must address them. However, sometimes teachers try multiple methods to no avail. PLCs provide a community of expertise for possibilities in addressing difficult student learning obstacles.

PLCs are important because collaboration is truly a better method to solution finding than autonomy. With new technologies creating an ever-changing landscape of necessary knowledge and skills and national, state, and local policies creating even more pressures for student performance, one teacher alone in one room with often twenty-five or more students can no longer rely simply on his knowledge and skills to meet the current requirements for successfully educating students. Only by pulling the expertise of his colleagues and providing his expertise to his colleagues within a PLC will he, through collaboration and interdependence, be able to provide the best learning opportunities for his students.

\section{Project-Based Learning (PBL)}

Active learning is an attempt to expand the single one-size-fits-all lecture approach to teaching to one that allows more students to operate in their comfort zone at least part of the time ${ }^{[13]}$. Benjamin $^{[14]}$ describes active learning in this way: "Active learning connotes an array of learning situations in and out of the classroom in which students enjoys hands-on and minds-on experiences.” Active learning strategies have proven to be very effective in enhancing student learning, and Project-Based Learning falls within that category ${ }^{[13]}$.

Project-Based Learning (PBL) is centered on a project that is characterized by a well-defined outcome, or deliverable, and an ill-defined task. The project outcome can be thought of as the product a student or team is developing and something that they can easily describe to their

Proceedings of the 2009 ASEE Gulf-Southwest Annual Conference

Baylor University

Copyright ( 1 2009, American Society for Engineering Education 
parents. The project itself is generally information-rich but the directions are kept to a minimum. The richness of the information is often directly related to the quality of the learning and level of student engagement. Additionally, the information is often multifaceted and includes background knowledge, graphs, pictures, specifications, generalized and specific outcome expectations, narrative, and, in many cases, the formative and summative expectations. The process often results in the emergence of various learning outcomes in addition to the ones anticipated.

The projects promote study and investigation within authentic contexts; encourage the growth of student responsibility, initiative, decision making and intentional learning; cultivate collaboration among students and teachers; utilize dynamic, interdisciplinary, and generative learning activities that promote higher-order thinking processes to help students develop rich and complex knowledge structures; and assess student progress in content and learning-to-learn by using realistic tasks and performances ${ }^{[15]}$. The projects encourage students to utilize everything they know, including life experiences from outside of school. This creates vital connections for the students, both between different courses as well as real-life situations. The learning students experience is dynamic as students use various processes and methods to explore the project. While specific learning outcomes are targeted by projects, the individual knowledge and skills each group of student address during the course of projects will vary. This framework allows for the greatest learning potential to occur, as students can be challenged to the maximum of their abilities. Within this learning situation, high-performing students exceed the base expected learning outcomes, and lower-performing students have a framework for demonstrating their knowledge and skills even if not completely mastering all the expected concepts. Additionally, students who may not perform well in a traditional academic-testing environment may excel at understanding real-world issues; for example, they may have worked on car engines and be very familiar with practical considerations such as gear size and belt tensioning.

\section{Integrating PBL and PLC}

Developing the rich projects and dynamic learning environment for true Project-Based Learning (PBL) can be daunting. Common first reactions from teachers include:

I do not have any good project ideas...

I do not have time to develop PBL lessons...

The integration of Professional Learning Communities and Project-Based Learning serve to address both those issues.

Professional Learning Communities are the ideal environment for developing Project-Based Learning lesson plans and allow for better leveraging of resources and learning scaffolding. Group brainstorming is a very effective way of generating ideas in a short amount of time and teamwork allows for the workload to be shared by several teachers. While Type I PLCs (teachers of the same discipline) can share ideas about the best ways to convey certain content; Type II PLCs (teachers in different disciplines) can generate projects that bridge across subject boundaries and as such are better at developing both problem-solving and critical-thinking skills. Projects involving multiple subjects help make the learning relevant to more students (i.e. some are attracted by the science, some by the math, some by the history). In addition, projects that cross classroom boundaries are easier to "fit" amongst the many other demands on class time. It is the integration of type II PLCs and PBLs that will results in the most synergistic arrangement.

Proceedings of the 2009 ASEE Gulf-Southwest Annual Conference Baylor University

Copyright $\Subset$ 2009, American Society for Engineering Education 
PLCs are necessary to any reform effort like Project-Based Learning because peer colleagues can provide non-evaluative feedback as well as socially supportive and positively pressuring environments. This kind of feedback within these environments allows teachers to challenge themselves pedagogically without fear of being evaluated while being supported to be responsible for changing their practice for student success, which is necessary within in the current data-driven decision making educational culture. Thus, data through standardized tests and benchmark assessments has forced reform. However, PLCs provide a network for teachers to rely upon to change their practice to meet those reform efforts. In fact, research shows that through a PLC environment teachers are able to be more innovative and experimental pedagogically $^{[16]}$. However, some of the most innovative and research-based pedagogical practices like Project-Based Learning that show gains in student improvement require teachers to rethink their practice in ways that are often time-consuming. Additionally, some of these best practice ideas require innovation of thinking about teaching in ways that many teachers have not thought about teaching previously. Nevertheless, networks like PLCs have the potential to pool "ideas on which any member can draw and as one idea or practice is transferred, the inevitable process of adaptation and adjustment to different conditions is rich in potential for the practice to be incrementally improved by the recipient and then fed back to the donor in a virtuous circle of innovation and improvement" ${ }^{\text {"[17] }}$. In fact, PLCs allow teachers to collectively pull their time resources as well as their expertise to make these much-needed pedagogical changes and raise the rigor of their academic practice. However, these communities not only help change

pedagogical practice, but sustain the processes ${ }^{[18,19]}$ that assist school reform. And, that sustainment is the key to continued school reform and continuous school improvement.

While PLCs can assist with any reform effort, when implementing Project-Based Learning, they are especially significant due to the amount of time and resources needed to create projects, both within a discipline and even more so, between disciplines. The most effective projects are crossdisciplinary and without teachers coming together in a PLC to create projects and then reflect on the process, rigor, and effectiveness of those projects in providing student academic success once they are completed, Project-Based Learning will be difficult at best to implement. Additionally, in schools that are simply trying to create within subject PBLs, the riskiness of the teacher paradigm shift in not only his or her teacher role, but the whole process of creating and implementing the PBL requires the assistance of his or her colleagues. Thus, PLCs are significantly important in the implementation of PBL.

\section{Ongoing and Future Work}

For PBL to occur, teachers need to view themselves as facilitators of knowledge. This change in role requires a shift in thinking about role, which is contrary to many of the models teachers have experienced of other teachers. Additionally, teachers feel the need to "solve" problems in students' thinking for them. However, in the moments of teacher refrain is often when students come up with their own problem-solving strategies. This change in role requires quite a bit of risk-taking on the part of the teacher. However, teachers have to be able to risk-take in order to allow their students to risk-take. Risk-taking is difficult, but within a professional learning community, it is easier to rely on the reflective help of colleagues. In fact, this type of classroom role risk-taking usually has to occur prior to the belief that a change in role is best, which is often

Proceedings of the 2009 ASEE Gulf-Southwest Annual Conference Baylor University

Copyright (C) 2009, American Society for Engineering Education 
contrary to the natural processes of teacher identity. Yet, with PBL, teachers usually have to behave differently and reap the results to find out that learning occurs. Belief is not needed prior to behavior change because usually teachers believe they need to control the learning situation. And, with PBL, the learning occurs due to the onus of learning being placed on the students as their responsibility. In fact, a number of case studies in mathematics, science, and literacy document how teachers who implement more inquiry-based approaches give students the opportunities to share their knowledge, thus creating conditions that challenge their own knowledge and practices ${ }^{[20,21]}$. So, teachers often have to experience students' successes to reform their teaching practices instead of reforming their teaching practices and then allowing student success to occur. This kind of belief following experience idea requires that teachers rely on their professional learning communities to assist them through this risk-taking process.

The success of this model seems to be based as much on the effectiveness of the collaboration developed by the Professional Learning Communities as on the successful implementation of Project-Based Learning in the classroom. Currently, the North Texas STEM (Science, Technology, Engineering and Math) Center future involves collaborating with the Waco Independent School District to incorporate Project Based Learning (PBL) through the development of Professional Learning Communities (PLCs) in their high schools. PLCs at three different high schools have been collaborating to develop PBL experiences for their current courses and tackling the issues of implementation and assessment.

The collaboration between the North Texas STEM Center and the Waco high schools began with integrated workshops over four days during the summer of 2008. Teachers and administrators from all three schools were present, and were assigned to mixed groups so each group would have representatives from all three schools as well as a mixture of math and science teachers. Parallel sessions were run to discuss the pedagogical and implementation issues involved PBLs and PLCs. Additional sessions focused on specific technologies that could aid in the process, as well as sessions on assessing PBLs.

During this process, the teachers were active participants in two different PBLs, one of which is the development of Stage-Storage relationships, the relationships between water depth and volume that are critical for water resource engineers. For this PBL, small teacher groups were asked to develop a relationship between stage and storage for a non-uniform glass container. Initially, no group understood the project objective due to the vocabulary being used. This was purposely done so as to lead into a discussion of assumed vocabulary and prior knowledge. After this discussion, the groups were then told to develop the water depth and volume relationship for the container, where they only had beakers and a ruler as instruments, and a couple of sheets of paper to document their results.

Being active participants in the process is important to the teachers as it takes the theoretical issues being discussed and makes them concrete. They can immediately relate to the importance of posing an intriguing and/or relevant story to capture the interest of the class, as well as the uncomfortable nature of not having explicit instructions to follow. However, it is equally important to de-brief the experience with the teachers immediately afterwards so as to make sure the content rigor is maintained and that the experience is not left at a purely "fun" level. For example, in the Stage-Storage PBL, the consensus of all groups was surprise at how many

Proceedings of the 2009 ASEE Gulf-Southwest Annual Conference Baylor University

Copyright $\Subset$ 2009, American Society for Engineering Education 
mathematical and sciences issues and concepts came up in something as simple as measure water in a glass container. While no two groups had the exact same discussion, in general there topics included: dependent and independent variables, unit systems, measurement accuracy, number of trials for confidence in an answer, averages, linear relationships, nonlinear relationships, and piece-wise linear curves. However, part of the role of the instructor was to ask questions to get them to explore those issues, as well as to make them aware of the learning they were doing. If the instructor is not active as a facilitator in this process, much of the possible learning gains can be lost as the students are not aware to their own learning.

On the last day, the time was devoted to get teacher groups started in trying to see how they could develop PBLs that would be applicable to their own classes. This session asked the teachers to brainstorm together, trying to identify interesting problems they could pose their students and then tie them into explicit Texas Essential Knowledge and Skills (TEKS) objectives for their course. Once course specific TEKS were identified, they were then asked to consider what other disciplines could also be incorporated naturally into the project idea.

The work done on the last day of the summer workshop provided the foundation for the teachers to develop PBLs at their schools in the PLCs. Over the course of the fall of 2008, the teachers of a specific class collaborated with one another in the development of PBLs that would be implemented in the spring of 2009. Future research results will focus on assessment of the collaboration and implementation parameters at the various schools and will study the correlation of the two with measures of student achievement.

\section{References}

1. Argyris, C. and D. Schon. (1978) Organizational learning: A theory of action perspective Reading, MA: Addison-Wesley.

2. Garvin, D.A. (1993). Building a learning organization. Harvard Business Review: p. 78-91.

3. Hedberg, B. (1981). How organizations learn and unlearn, in Handbook of organizational design, P.C.N.W.H. Starbuck, Editor. University Press: New York: Oxford. p. 9-11.

4. Huber, G. (1991). Organizational learning: The contributing processes and the literatures. Organization Science, 1: p. 88-115.

5. Rait, E. (1995). Against the current: Organizational learning in schools, in Images of schools: Structures and roles in organizational behavior, S.B. Bacharach and B. Mundell, Editors. Sage: Thousand Oaks, CA. p. 71-107.

6. Louis, K.S. and S. Kruse. (1995) Professionalism and community: Perspectives on reforming urban schools Thousand Oaks, CA: Corbin.

7. McLaughlin, M. and J. Talbert. (2001) Professional communities and the work of high school teaching. Chicago, IL: The University of Chicago Press.

8. McLaughlin, M. and J. Talbert. (2006) Building school-based teacher learning communities: Professional strategies to improve student achievement. New York: Teachers College Press.

9. Little, J.W. (1993). Teachers' professional development in a climate of educational reform. Educational Evaluation and Policy Analysis, 15(2): p. 129-151.

10. Louis, K.S., S. Kruse, and H. Marks. (1996). Schoolwide professional community, in Authentic achievement: Restructuring schools for intellectual quality, F.M.N. Associates, Editor. Jossey-Bass: San Francisco. p. 179-203.

11. Cochran-Smith, M. and S. Lytle. (1999). Relationships of knowledge and practice: Teacher learning in communities. Review of Research in Education, 24: p. 249-305.

12. Giles, C. and A. Hargreaves. (2006). The sustainability of innovative schools as learning organizations and professional learning communities during standardized reform. Educational Administration Quarterly, 42(1): p. 124-156.

Proceedings of the 2009 ASEE Gulf-Southwest Annual Conference Baylor University

Copyright (C) 2009, American Society for Engineering Education 
13. Bonwell, C.C. and J.A. Eison. (1991). Active Learning: Creating Excitement in the Classroom. ASHEERIC Higher Education Reports, The George Washington University: Washington, DC

14. Mathie, V.A., et al. (1993). Promoting active learning in psychology courses, in Handbook for enhancing undergraduate education in psychology. American Psychological Association: Washington, DC. p. 183214.

15. Wilson, B. and M. Ryder. (1996). Dynamic Learning Communities: An Alternative to Designed Instructional Systems, in Proceedings of Selected Research and Development Presentations at the 1996 National Convention of the Association for Educational Communications and Technology Indianapolis, IN.

16. Byrk, A., E. Camburn, and K.S. Louis. (1999). Professional community in Chicago elementary schools: Facilitating factors and organizational consequences. Educational Administration Quarterly, 35(5): p. 751-781.

17. Hargreaves, D. (2003). From improvement to transformation (Keynote address), in Sixteenth annual conference of the International Congress for School Effectiveness and Improvement: Sydney, Australia.

18. Seashore, K.R., A.R. Anderson, and E. Riedel. (2003). Implementing arts for academic achievement: The impact of mental models, professional community and interdisciplinary teaming, in Seventeenth Annual Conference of the International Congress for School Effectiveness and Improvement: Rotterdam, Netherlands.

19. Toole, J. (2001) Mental models, professional learning communities, and deep structure of school change: Case studies of service learning. Minneapolis, MN: University of Minnesota.

20. Hufferd-Ackles, K. (1999). Learning by all in a math-talk learning community. Northwestern University: Evanston, IL.

21. Reiser, B.J., et al. (2000). Investigating the mutual adaptation process in teachers' design of technologyinfused curricula, in International Conference of the Learning Sciences: Ann Arbor, MI.

\section{JIM MORGAN}

Dr. Morgan currently serves as an Associate Professor of Civil Engineering at Texas A\&M University. He is the father of two daughters and the spouse of an engineer. His research interests include structural mechanics and dynamics, Earthquake Engineering, and Engineering Education.

\section{LUCIANA R. BARROSO}

Dr. Barroso currently serves as an Associate Professor of Civil Engineering at Texas A\&M University. Her research interests include engineering education, structural control, structural health monitoring, system identification, linear and nonlinear dynamics of Structures, earthquake engineering, and probabilistic hazard analysis.

\section{KRISTIN S. HUGGINS}

Kristin Shawn Huggins is a PhD student in Public School Administration in the Department of Educational Administration and Human Resource Development (EAHR) at Texas A\&M University. Her research interests include urban high school reform, equity in education, and professional development. 